\title{
Congrès National Suicide
}

Bien que relativement rare, le suicide d'un patient représente un événement éprouvant pour le médecin. Par contre, les comportements suicidaires sont hélas relativement fréquents, surtout parmi les jeunes, et représentent des événements marquants, douloureux et difficiles à vivre également pour leur entourage.
Le Congrès «Suicide!» vise à réunir de nombreux acteurs provenant de différents domaines tels que la médecine de premier recours, la santé mentale, la prévention du suicide, l'intervention de crise, l'accompagnement psycho-social et l'action sociale afin de promouvoir l'échange et la concertation.

\section{Participez à cette occasion unique de partage d'expérience, d'échange et d'apprentissage!}

Toutefois, une évolution défavorable pourrait souvent être évitée par un dépistage précoce et un traitement adéquat. Il est possible d'agir sur les comportements suicidaires, car ils peuvent être identifiés et traités. Le médecin joue un rôle important dans le dépistage et l'accompagnement de personnes suicidaires. En effet, selon une étude menée dans les années 1990 par le Professeur K. Michel, 4 personnes sur 5 qui se sont suicidées étaient suivies par un médecin au moment de leur décès. Souvent elles étaient suivies à cause de troubles somatiques, un signe précurseur parmi d'autres. Le médecin de premier recours a ainsi une fonction essentielle dans le dépistage/diagnostic et le traitement lors de situations de crise.
Si vous vous sentez concerné-e-s par le suicide, l'intervention de crise, la santé mentale ou si le sujet vous intéresse, vous êtes cordialement invité-e-s à participer à cette occasion unique d'échange et de «réseautage».

Le congrès offre la possibilité de participer à différents ateliers. Animés par des acteurs renommés du domaine de la prévention, intervention et postvention du suicide, ces ateliers représentent des opportunités uniques de partage d'expérience, d'échange et d'apprentissage.

\section{Information \\ et inscription \\ Organizers (Schweiz) \\ $\mathrm{GmbH}$, Obere Egg 2, \\ CH-4312 Magden \\ Tél. 06183698 78, \\ Fax 0618369877 \\ E-Mail: registration@ \\ organizers.ch \\ www.organizers.ch}

\author{
Jeudi 18 mars 2010 \\ 7h 30 Inscription \\ $8 \mathrm{~h} 30$ Accueil et introduction \\ 9 h 00 Key Note Session 1 - Suicidalité aïgue \\ et désespoir \\ Prof. Dr méd. Daniel Hell \\ Klinik Hohenegg, Meilen \\ $10 \mathrm{~h} 00$ Pause-café /Networking \\ $10 \mathrm{~h} 30$ Ateliers \\ $12 \mathrm{~h} 00$ Lunch / Networking \\ $13 \mathrm{~h} 30$ Key Note Session 2 - Suicidalité \\ chronique et automutilation \\ Dr Annabel McQuillan, Jussy \\ 14h 45 Ateliers \\ $15 \mathrm{~h} 30$ Pause-café /Networking \\ $16 \mathrm{~h} 00$ Ateliers \\ $16 \mathrm{~h} 45$ Conclusion et clôture $1^{\mathrm{er}}$ jour \\ 17h 30 Apéro \\ $18 \mathrm{~h} 30$ Knowledge Dinner \\ Dr Benedetto Saraceno, Genève
}

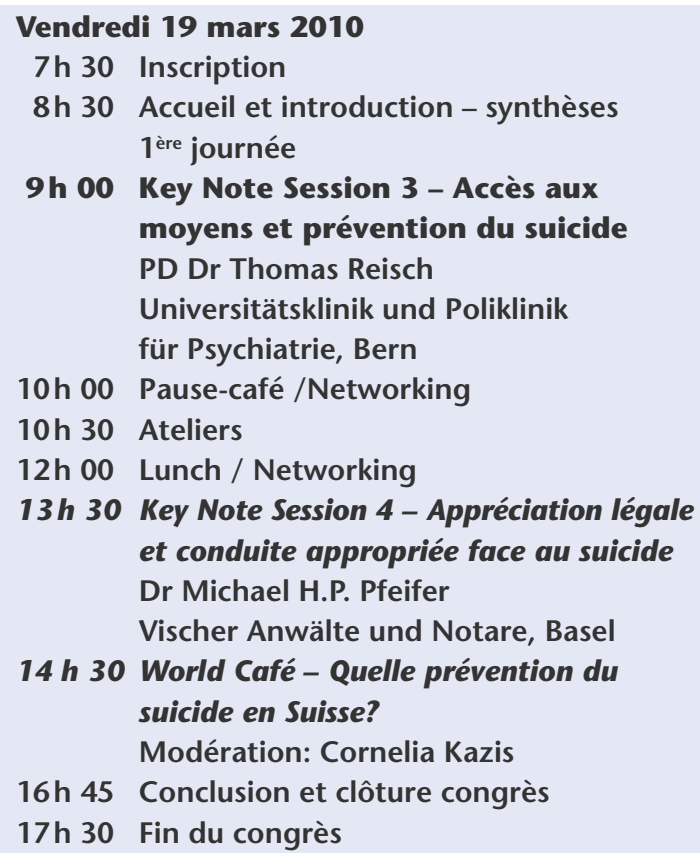

